\title{
Ensino por investigação nas aulas de matemática do curso de licenciatura em química
}

\author{
Teaching by research in the Mathematics classes of the Chemistry \\ teacher training course
}

\author{
Karina Alessandra Pessoa da Silva ${ }^{1}$ \\ Rodolfo Eduardo Vertuan ${ }^{2}$ \\ Jaqueline Munise Guimarães da Silva ${ }^{3}$
}

\section{Resumo}

Neste artigo trazemos à baila uma pesquisa realizada no contexto de aulas de matemática de um curso de Licenciatura em Química na qual buscamos configurar atividades experimentais investigativas em atividades de modelagem matemática. Fundamentamo-nos em aportes teóricos do Ensino por Investigação, que consiste em uma abordagem didática que cria um ambiente investigativo, bem como na Modelagem Matemática, entendida como alternativa pedagógica para ensinar matemática. Subsidiamos nossas análises nos relatórios escritos de três atividades de modelagem matemática desenvolvidas por três grupos de alunos de diferentes turmas do curso de Licenciatura em Química na disciplina de Cálculo Diferencial e Integral 1 de uma universidade federal do Paraná. A análise qualitativa, inspirada na Research Design, dos relatórios entregues pelos alunos, possibilitou-nos realizar agrupamentos que caracterizam atividades experimentais investigativas como um jeito de "visualizar" os conceitos da área de química na prática; como meio de possibilitar a verificação/confirmação de dados obtidos via outras fontes (rótulo, literatura, etc.); como precursora de reflexões relacionadas a aspectos socioculturais; como disparadora de discussões matemáticas contextualizadas; como possibilidade de os alunos, desde o início do curso, vivenciarem ações características de uma atividade de pesquisa, tais como produzir e organizar dados, utilizando-os para pensar sobre um problema.

Palavras chave: Ensino por Investigação; Modelagem Matemática; Atividade experimental investigativa.

\section{Abstract}

In this paper we bring to light a research carried out in the context of mathematics classes of a Chemistry teacher training course in which we seek to establish experimental investigative activities in mathematical modeling activities. We are based on the theoretical contributions of Teaching by Research that consists of a didactic approach that creates an investigative environment, as well as in the Mathematical Modeling understood as a pedagogical alternative to teach mathematics. We subsidized our analyzes in the written reports of three mathematical modeling activities developed by three groups of students of different classes of the Degree in Chemistry in the discipline of Differential and Integral Calculus 1 of a federal university in Paraná. The qualitative analysis, inspired by Research Design, of the reports delivered by the students allowed us to make groupings that characterize

\footnotetext{
${ }^{1}$ Universidade Tecnológica Federal do Paraná | karinasilva@utfpr.edu.br

${ }^{2}$ Universidade Tecnológica Federal do Paraná | rodolfovertuan@utfpr.edu.br

3 Universidade Tecnológica Federal do Paraná | jaque19343@gmail.com
} 
experimental investigative activities as a way to "visualize" the concepts of the area of chemistry in practice; as a means of enabling verification / confirmation of data obtained from other sources (label, literature, etc.); as precursor of reflections related to sociocultural aspects; as a trigger for contextualized mathematical discussions; as a possibility for the students, from the beginning of the course, to experience actions characteristic of a research activity, such as producing and organizing data, using them to think about a problem.

Keywords: Research Teaching; Mathematical Modeling; Experimental investigative activity.

\section{Introdução}

A disciplina de Cálculo Diferencial e Integral está presente no Projeto Político Pedagógico de diferentes cursos do Ensino Superior. Em cursos nos quais tal disciplina é considerada de aplicação, estabelecer relações entre os conteúdos abordados e aqueles próprios ao contexto do curso pode se constituir em um obstáculo seja para os alunos, seja para os professores que a ministram.

Com vistas a superar esse obstáculo, pesquisadores da área de Educação Matemática têm empreendido esforços em incorporar atividades nas quais os alunos escolhem temas/situações/problemas de interesse e resolvem-nos utilizando seus conhecimentos, articulando-os a conhecimentos matemáticos (ALMEIDA; SILVA, 2017; ARAÚJO; CAMPOS, 2015; FERRUZZI; ALMEIDA, 2015; IGLIORI; BELTRÃO, 2015; SILVA, 2017).

Em nossas aulas, temos nos empenhado em utilizar uma alternativa pedagógica na qual os alunos, a partir de uma situação inicial chegam a uma solução por meio de procedimentos matemáticos. O encaminhamento da situação inicial (problemática) até a situação final (solução) é orientado por ações que caracterizam atividades de modelagem matemática. As atividades de modelagem matemática podem ser entendidas como atividades investigativas que são "propostas aos estudantes e que envolvem a resolução de problemas mal definidos e pouco estruturados" (BORGES, 2002, apud GOMES; BORGES; JUSTI, 2008, p. 187).

Levando em consideração as configurações para o desenvolvimento de uma atividade de modelagem matemática, estas possibilitam criar um ambiente investigativo próprio daquele permeado no Ensino por Investigação. Isso se deve ao fato de que o Ensino por Investigação pode "estar vinculado a qualquer recurso de ensino desde que o processo de investigação seja colocado em prática e realizado pelos alunos a partir e por meio das orientações do professor" (SASSERON, 2015, p. 58).

Dentre as atividades de modelagem matemática desenvolvidas no contexto da disciplina de Cálculo Diferencial e Integral 1 de um curso de Licenciatura em Química de uma universidade federal do norte do Paraná, destacam-se aquelas voltadas ao trabalho experimental, devido à natureza do referido curso. Todavia, a abordagem realizada está em consonância com o trabalho experimental de investigação como caracterizado por Fernandes e Silva (2004). Nesta abordagem os alunos são colocados diante de

[...] situações que tenham realmente carácter problemático, de modo a que sejam encorajados a levantar questões, a planear experiências simples, visando a testagem de uma dada hipótese de trabalho, a fazer previsões, a observar semelhanças e diferenças, a usar uma pluralidade de métodos, a comunicar as suas ideias e a reflectir criticamente sobre todo o percurso investigativo (FERNANDES; SILVA, 2004, p. 46). 
Entendendo que o trabalho experimental de investigação pode ser caracterizado como uma atividade investigativa, em que o aluno "raciocina sobre o problema proposto e procura respostas para sua solução a partir da proposição de hipóteses e análise dos dados, manifestando assim, suas habilidades de cognição" (SUART; MARCONDES, 2009, p. 51-52), neste artigo nos debruçamos sobre a questão de pesquisa: Como se configuram atividades experimentais investigativas desenvolvidas por alunos do curso de Licenciatura em Química no contexto de atividades de modelagem matemática?

Os dados que subsidiam nossas análises foram obtidos com alunos ingressantes no curso de Licenciatura em Química nos anos de 2015, 2016 e 2017 ao desenvolverem, em grupos, atividades experimentais investigativas orientadas pela professora de Cálculo Diferencial e Integral 1.

Neste artigo, apresentamos resultados e inferências acerca da questão de pesquisa, tomando como ponto de partida considerações sobre Modelagem Matemática e Ensino por Investigação, apresentadas na segunda seção. Em seguida, apresentamos os aspectos metodológicos considerados na pesquisa. Na quarta seção apresentamos uma descrição das atividades desenvolvidas, para em seguida realizar uma análise das mesmas à luz da fundamentação teórica. Finalizamos tecendo nossas considerações finais.

\section{Modelagem Matemática no contexto do Ensino por Investigação}

O Ensino por Investigação tem como objetivo a formação de estudantes com capacidade para argumentar, levantar hipóteses e realizar análise de dados oriundos de sua realidade. Trata-se de uma abordagem didática que possibilita abordar conceitos, realizar trabalho colaborativo, desenvolver a argumentação dos alunos (SASSERON, 2015).

O que se defende é que essa abordagem didática cria um ambiente investigativo em que o ensino se aproxima de forma simplificada dos processos de um trabalho científico (CARVALHO, 2013). Essa aproximação se deve ao fato de os alunos se engajarem "com as discussões e, ao mesmo tempo em que travam contato com fenômenos naturais, pela busca de resolução de um problema, exercitam práticas e raciocínios de comparação, análise e avaliação bastante utilizadas na prática científica" (SASSERON, 2015, p. 58). Dessa forma, alunos engajados em desenvolver uma atividade no âmbito do Ensino por Investigação, têm papel ativo "na construção de entendimento sobre os conhecimentos científicos" (SASSERON, 2015, p. 58).

Na literatura existem diferentes caracterizações para Ensino por Investigação. Zômpero e Laburú (2011) fizeram um levantamento dessas caracterizações e inferiram que, no contexto do ensino de Ciências, no Ensino por Investigação "deve haver um problema para ser analisado, a emissão de hipóteses, um planejamento para a realização do processo investigativo, visando a obtenção de novas informações, a interpretação dessas novas informações e a posterior comunicação das mesmas" (ZÔMPERO; LABURÚ, 2011, p. 74-75). Neste contexto, os alunos se envolvem em atividades investigativas com o objetivo de se obter uma solução para um problema previamente estabelecido.

Corroboramos com Sasseron (2015) quando afirma que o Ensino por Investigação "extravasa o âmbito de uma metodologia de ensino apropriada apenas a certos conteúdos e temas, podendo ser colocada em prática nas mais distintas aulas, sob as mais diversas formas e para os diferentes conteúdos" (p. 58). Nesse sentido, consideramos que tal 
abordagem didática é adequada para articular conteúdos matemáticos aos estudados no contexto dos cursos superiores.

Para isso, alinhados aos apontamentos de Gomes, Borges e Justi (2008), no âmbito da Educação Matemática, nos apoiamos em atividades investigativas configuradas como atividades de modelagem matemática. Isso se deve ao fato de que atividades de modelagem ${ }^{4}$ requerem dos alunos a formulação de um problema e a definição de metas para sua resolução, a definição de hipóteses, a formulação de previsões e a apresentação de explicações e respostas para a situação em estudo, bem como a comunicação destas respostas e/ou explicações para outros (ALMEIDA; FERRUZZI, 2009). O desenvolvimento de atividades de modelagem, geralmente, é realizado de forma cooperativa, em que o trabalho em grupo é seu aporte. Com isso, diferentes conhecimentos são compartilhados entre os alunos e entre alunos e professor.

Segundo Almeida e Ferruzzi (2009, p. 120-121), uma atividade de modelagem desencadeia um conjunto de ações dos envolvidos tais como:

a busca de informações, a identificação e seleção de variáveis, a elaboração de hipóteses, a simplificação, a obtenção de uma representação matemática (modelo matemático), a resolução do problema por meio de procedimentos adequados e a análise da solução que implica numa validação, identificando a sua aceitabilidade ou não.

No desenvolvimento de uma atividade de modelagem, o que se objetiva é a busca por uma solução para o problema. Para essa busca, há necessidade de perpassar por uma ou mais representações matemáticas para um objeto ou fenômeno não-matemático, criando "uma complexa relação estrutural entre duas entidades de diferente natureza epistemológica: a situação a ser modelada e o sistema matemático" (ALMEIDA; SILVA, 2015, p. 45). Nesse sentido,

[...] aos buscarmos modelar algum fenômeno, uma situação-problema, devemos saber coligir os dados por certo crivo lógico, que resulte em uma formulação que expresse certa regularidade entre os acontecimentos da situação ao fenômeno estudado, para assim gerar um modelo que nos valha para formular preceitos, desvendar causas ou efeitos. Um modelo gerado não é a 'realidade', mas algo que busca aproximar-se desta realidade em certa escala. Modelo que por meio de representações simbólicas permita-nos entendimento desta 'realidade' (BIEMBENGUT, 2016, p. 119).

Tais representações simbólicas, a literatura em Educação Matemática convencionou denotar por modelo matemático - um sistema conceitual, descritivo ou explicativo que tem por finalidade descrever, explicar e mesmo predizer o comportamento do fenômeno (ALMEIDA; SILVA; VERTUAN, 2012).

Corroboramos com Souza e Justi (2010, p. 4) quando afirmam que, para deduzir um modelo, "não existem regras fixas ou um único caminho a ser seguido", todavia, há de se considerar "a finalidade da construção de um modelo em um determinado contexto". No contexto de aulas de Matemática, a finalidade de construir modelos matemáticos é o de ensinar e aprender matemática.

\footnotetext{
${ }^{4}$ Em alguns momentos do texto utilizamos o termo modelagem para nos referirmos à modelagem matemática.
} 
Segundo Almeida e Silva (2017, p. 209), a "introdução e o uso da modelagem matemática nos diversos níveis de escolaridade e em diferentes cursos e disciplinas remete, entretanto, ao uso, à aplicação e à construção de conhecimento em Matemática". Geiger, Ärlebäck e Frejd (2016) argumentam que existem dois temas principais para a inclusão da modelagem como parte da prática de sala de aula:

O primeiro baseia-se na premissa de que a capacidade de modelar e encontrar soluções para situações relacionadas à vida é uma competência que pode servir ao indivíduo na vida cotidiana e no local de trabalho. 0 segundo apresenta a modelagem como um meio pelo qual os indivíduos constroem novos conhecimentos matemáticos ou reconstroem o conhecimento que já adquiriram ao se envolver com o processo de modelagem (GEIGER; ÄRLEBÄCK; FREJD, 2016, p. 208, tradução nossa).

Esses autores ainda defendem que, dependendo das razões do professor para incluir modelagem matemática em suas aulas, diferentes tipos de atividades podem ser utilizados. No âmbito do curso de Licenciatura em Química, atividades experimentais investigativas têm sido o enfoque que permeia nossas pesquisas. Nessas atividades, "o aluno se envolve na resolução de um problema e, se mobiliza à procura de uma metodologia para a sua *resolução" (SUART; MARCONDES, 2009, p. 55).

Para Silva e Trivelato (2017, p. 150), "a promoção de atividades investigativas com enfoque experimental possibilita a integração de objetivos conceituais e epistêmicos", visto que conhecimento empírico articulado com conhecimento de natureza distinta exige que os alunos tomem decisões "julgando a consistência dos diversos dados obtidos, a validade de um determinado modelo teórico para explicá-los e as evidências que justificam suas decisões". Isso porque neste tipo de atividade, os alunos desenvolvem a capacidade "de elaborar hipóteses, testá-las e discuti-las, aprendendo sobre os fenômenos estudados e os conceitos que os explicam, alcançando os objetivos de uma aula experimental, a qual privilegia o desenvolvimento de habilidades cognitivas e o raciocínio lógico" (SUART; MARCONDES, 2009, p. 51).

Com os apontamentos supracitados, a afirmação de Rosa, Suart e Marcondes (2017, p. 56) de que é "indicado que o licenciando tenha acesso a novas metodologias de ensino e de aprendizagem, para que possa refletir criticamente sobre qual a melhor abordagem a ser utilizada em cada sala de aula", bem como o entendimento de que em atividades de modelagem "realidade (origem da situação inicial) e matemática (área em que os conceitos e os procedimentos estão fundamentados) passam a se integrar e, em diferentes momentos, conhecimentos matemáticos e conhecimentos extramatemáticos são acionados e/ou produzidos e integrados" (ALMEIDA; SILVA, 2012, p. 628), é que propusemos modelagem nas aulas de Cálculo ${ }^{5}$ do curso de Licenciatura em Química.

\section{Aspectos metodológicos da pesquisa}

Com vistas a evidenciar configurações de atividades experimentais investigativas em atividades de modelagem matemática no contexto de uma disciplina de Cálculo Diferencial

\footnotetext{
${ }^{5}$ Utilizamos o termo Cálculo para nos referirmos a Cálculo Diferencial e Integral 1.
} 
e Integral 1 do curso de Licenciatura em Química, analisamos três atividades de modelagem desenvolvidas por alunos de uma universidade pública federal localizada no estado do Paraná.

A disciplina de Cálculo Diferencial e Integral 1, com carga horária de 108 horas/aula, do referido curso é ofertada no primeiro período letivo, com alunos ingressantes. Além dessa carga horária, no Projeto Político Pedagógico do curso de Licenciatura em Química, são inseridas 6 horas/aula, destinadas à atividade extraclasse, denotada por Atividades Práticas Supervisionadas (APS).

Dentre as atividades que geralmente são desenvolvidas nas APS, desde 2014, a professora (autora deste artigo) solicita que os alunos vivenciem uma atividade de modelagem matemática realizada em grupos (4 ou 5 integrantes) sob sua orientação com temas por eles escolhidos. A solicitação é feita no primeiro dia de aula e, ao longo do semestre letivo do curso, os alunos desenvolvem a atividade cientes de que os relatórios farão parte do corpus de dados de pesquisa desenvolvida pela professora na instituição. Com isso, assinam um termo de consentimento livre e esclarecido.

Para familiarizar os alunos com Modelagem Matemática, a professora desenvolve nas aulas regulares atividades desta natureza. $O$ procedimento de familiarização segue orientações propostas por Almeida, Silva e Vertuan (2012) que defendem uma introdução gradativa de atividades de modelagem matemática e tem como objetivo desenvolver no aluno a "habilidade de fazer modelagem" (ALMEIDA; SILVA; VERTUAN, 2012, p. 27).

Considerando a natureza experimental da Química, muitos dos grupos de alunos têm se dedicado a desenvolver atividades de modelagem matemática em que os dados que subsidiam a busca por uma solução para o problema são coletados no Laboratório de Química da instituição. Para a coleta de dados laboratoriais, nos anos de 2015 a 2017, os alunos contaram com o auxílio e a supervisão de uma aluna de iniciação científica (terceira autora deste artigo), também estudante do curso de Licenciatura em Química.

Considerando os alcances e os propósitos desta pesquisa, tratamos de três atividades desenvolvidas por três grupos de alunos nos anos de 2015, 2016 e 2017 (Quadro 1). A escolha está fundamentada nas características das atividades desenvolvidas - atividade experimental investigativa - bem como nos conteúdos matemáticos que delas emergiram pertencentes à ementa da disciplina de Cálculo. Para nossa análise, consideramos os registros escritos dos relatórios entregues pelos grupos de alunos, designados por G1, G2 e G3.

Quadro 1 - Temáticas investigadas pelos alunos do curso de Licenciatura em Química

\begin{tabular}{|c|c|c|c|}
\hline Grupo & G1-2015 & G2 - 2016 & G3-2017 \\
\hline Temática & $\begin{array}{c}\text { Avaliação da dureza e } \\
\text { da concentração de } \\
\text { cálcio em água mineral }\end{array}$ & $\begin{array}{c}\text { Teor de açúcar nos } \\
\text { refrigerantes e a taxa } \\
\text { metabólica basal }\end{array}$ & $\begin{array}{c}\text { Comportamento do } \\
\text { probiótico em relação } \\
\text { à temperatura }\end{array}$ \\
\hline
\end{tabular}

A abordagem de nossas análises se enquadra na metodologia de pesquisa qualitativa, inspirada na Research Design, mais especificamente no Design Experiments. Segundo Lesh (2002, p. 29), a Research Design "envolve novas maneiras de pensar sobre a natureza dos conhecimentos e das habilidades matemáticas em desenvolvimento dos alunos e novas maneiras de pensar sobre a natureza do ensino, da aprendizagem e da resolução de problemas eficazes" (tradução nossa). Em nossa pesquisa, essas "novas maneiras de pensar" foram se configurando ao longo do encaminhamento de nossas aulas desencadeadas por 
atividades de modelagem matemática desde o ano de 2014. Nesse período, as atividades de modelagem se estruturaram segundo um design que possibilitou a aprendizagem de Matemática a partir de atividades experimentais investigativas.

\section{Descrição das atividades de modelagem matemática}

Na atividade desenvolvida por G1 - Avaliação da dureza e da concentração de cálcio em água mineral -, os alunos enunciam como objetivo "Calcular a dureza da água através da concentração de cálcio presente em amostras de água mineral" ${ }^{\prime 6}$. Isso porque, segundo os mesmos, "a demanda por água mineral tem sido cada vez maior". Para empreender a investigação, consideraram 4 tipos de amostras - garrafas de marcas diferentes compradas em supermercado, sendo uma delas considerada o caso "curiosidade", o da água com gás e utilizam o método da Titulometria para analisar a dureza da água.

Figura 1 - Procedimentos realizados na atividade desenvolvida por G1

O método utilizado para a análise da dureza foi a Titulometria com EDTA-Na 0,02M, preto de eríocromo T como indicador, e uma solução tampão $\mathrm{NH}_{4} \mathrm{Cl} / \mathrm{NH}_{4} \mathrm{OH}(\mathrm{pH}=10)$.

Reagentes:

- EDTA 0,02M

- Preto de erocromo - T

- Solução Tampão pH = 10

Materiais:

- 4 pipetas volumétricas de $100 \mathrm{~mL}$

- 8 erlenmeyers de $250 \mathrm{~mL}$

- 4 béqueres de $150 \mathrm{~mL}$

- Suporte universal

- Bureta graduada de $25 \mathrm{~mL}$

- 1 pera

Lavou-se a bureta duas vezes com pequenas quantidades de solução de EDTA (ácido etilenodiaminotetracético) $0,02 \mathrm{~mol}^{\mathrm{L}} \mathrm{L}^{-1}$, escoando todo o líquido antes da adição do novo volume. Fixou-se a bureta de $25,00 \mathrm{~mL}$, com auxílio de uma garra metálica, em um suporte universal.

Em seguida, encheu-se até um pouco acima do zero da escala, com a solução titulante. Abriu-se a torneira para preencher a extremidade inferior da bureta; zerou-se de modo que a base do menisco do líquido na bureta tangenciasse a marca zero da escala. Transferiu-se, com o auxílio de uma pipeta volumétrica $100 \mathrm{~mL}$, uma amostra de água mineral (Amostra A) para um erlenmeyer de $250 \mathrm{~mL}$, juntamente com $2 \mathrm{~mL}$ de solução tampão $\mathrm{pH}=10$ e uma pitada do indicador NET (Negro de Eriocromo T).

Colocou-se o erlenmeyer sob a bureta e escoou-se a solução titulante, gota a gota, até a mudança de coloração. Fez-se a leitura correta do volume de titulante gasto na titulação. Repetiu-se duas vezes o processo, a fim de obter-se o volume médio gasto para mudança de cor. Calculou-se a dureza da água em termos de $\mathrm{mg}^{-{ }^{-1}}$ de $\mathrm{CaCO}_{3}$.

Fonte: Relatório dos alunos.

${ }^{6}$ Os textos que apresentamos entre aspas são retirados dos relatórios escritos entregues pelos alunos, fonte de dados desta pesquisa. 
Calcular a dureza da água significa mensurar a "concentração total de íons alcalinoterrosos na água, particularmente de cálcio $\left(\mathrm{Ca}^{2+}\right)$ e magnésio $\left(\mathrm{Mg}^{2+}\right)^{\prime}$, de modo que "água contendo elevadas quantidades de íons $\mathrm{Ca}^{2+}$, nomeadamente cálcio, é denominada por água dura".

No relatório entregue, os alunos apresentam os procedimentos tomados para a coleta de dados, bem como apresentam imagens do processo realizado (Figura 1). No caso deste grupo, observa-se riqueza de detalhes na descrição da atividade experimental. Acredita-se que há semelhança no formato do texto com o que realizam, possivelmente, nas aulas de laboratório do curso. Esse formato de organização e apresentação dos dados denota preocupação tanto em relação aos procedimentos quanto em relação à divulgação da pesquisa.

Os alunos apresentaram no relatório uma sequência de fotografias para ilustrar os procedimentos realizados (Figura 2).

Figura 2 - Fotos dos procedimentos realizados na atividade desenvolvida por G1

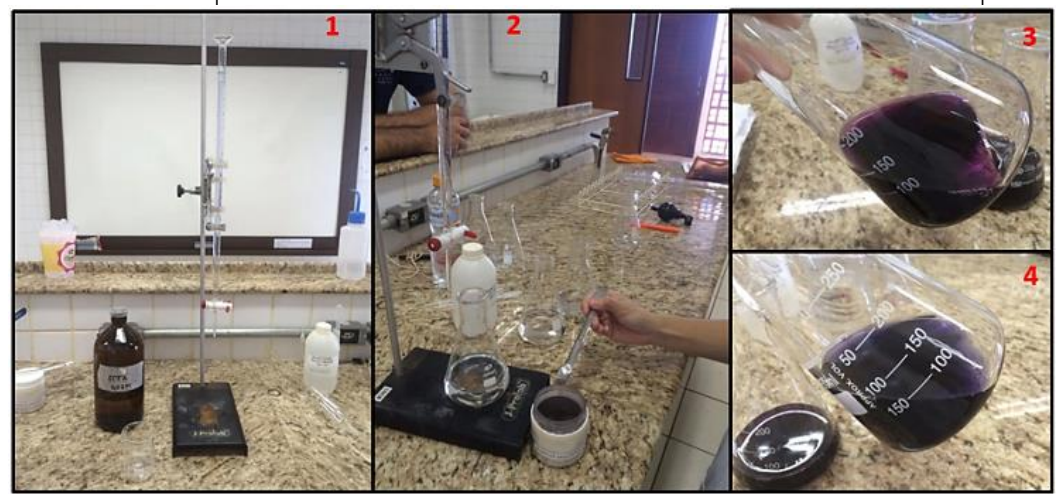

Fonte: Relatório dos alunos.

Como conclusão, os alunos afirmaram que "As amostras A e B encontram-se dentro dos padrões de águas mole (concentração inferior a $50 \mathrm{mg}$ de $\mathrm{CaCO}_{3}$ por litro de água). As amostras C e D apresentam concentração um pouco mais elevada do que as concentrações padrão, estando dentro dos padrões de água dura (150mg a 500mg de $\mathrm{CaCO}_{3}$ )".

Os conteúdos matemáticos presentes na resolução foram notação científica, proporção e função.

$\mathrm{Na}$ atividade desenvolvida por G2 - Teor de açúcar nos refrigerantes e a taxa metabólica basal -, com o objetivo de "calcular o teor de açúcar que uma pessoa pode consumir com base na sua TMB (taxa de metabolismo basal) e analisar a quantidade de açúcar existente nos refrigerantes, comparando com os dados apresentados no rótulo da embalagem", os alunos selecionaram 4 tipos de refrigerante de cola, de $600 \mathrm{~mL}: \mathrm{A}, \mathrm{B}, \mathrm{C}, \mathrm{D}^{7}$.

$A$ atividade experimental consistiu em ferver o refrigerante em uma panela, de modo que sobrasse apenas um caramelo, que seria o açúcar do refrigerante junto com o xarope e outros compostos (Figura 3).

\footnotetext{
${ }^{7}$ As marcas dos refrigerantes foram omitidas, visto que não é o objetivo de nosso artigo.
} 
Figura 3 - Procedimentos para cada amostra na atividade desenvolvida por G2

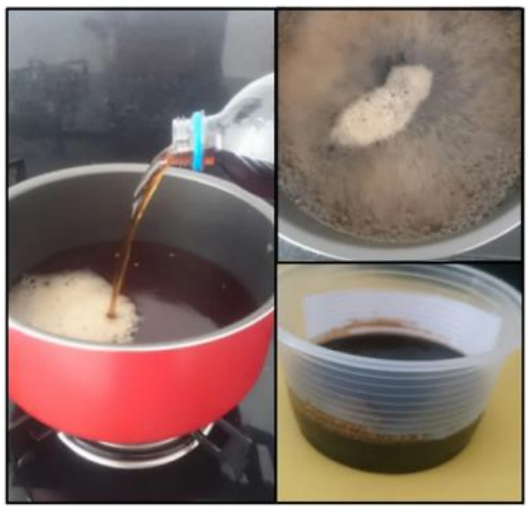

Fonte: Relatório dos alunos.

Após o desenvolvimento dos procedimentos, os alunos mediram a massa que sobrou da fervura de cada amostra e obtiveram os dados conforme apresentados no Quadro 2.

Quadro 2 - Dados quantitativos obtidos em cada amostra na atividade de G2

\begin{tabular}{|c|c|c|c|c|}
\hline Marca do refrigerante & A & B & C & D \\
\hline $\begin{array}{c}\text { Massa que sobrou após } \\
\text { fervura (em g) }\end{array}$ & 57,56 & 54,09 & 0,99 & 63,30 \\
\hline
\end{tabular}

Fonte: Relatório dos alunos.

Com estes dados foi possível comparar a quantidade de açúcar encontrada nos referidos refrigerantes, com a quantidade informada no rótulo da embalagem, estes últimos denominados pelos alunos de Dados Teóricos (D. Teórico). A comparação se deu por meio do gráfico de colunas da Figura 4.

Figura 4 - Comparação da quantidade de açúcar em refrigerantes: experimento versus rótulo

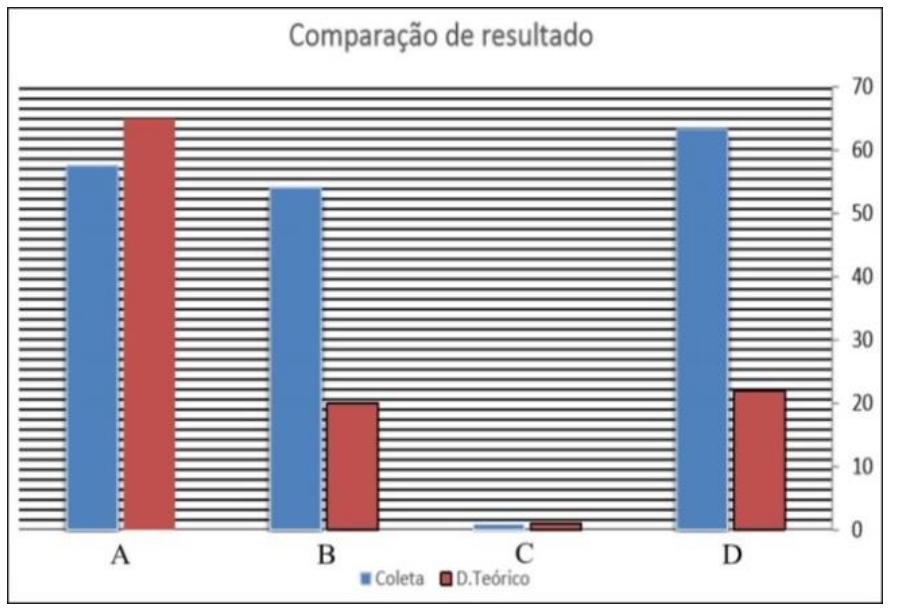

Fonte: Relatório dos alunos.

A partir da constatação, os alunos apontam que "a marca A e a marca C (do mesmo fabricante) apresentam quantidade de açúcar aproximada ao que as embalagens apresentam, chegam próximas, ao contrário da marca B e da marca D (do mesmo fabricante) que ficam distantes do que a embalagem apresenta. $O$ valor apresentado no rótulo pode ser um grande problema, pois a quantidade ' $x$ ' mostrada ao cliente não é 
verdadeira segundo a atividade experimental realizada, pois foi encontrado quase o dobro de açúcar".

Essa preocupação é que desencadeou a próxima investigação no âmbito da mesma atividade: "calcular a quantidade de açúcar que uma pessoa pode ingerir sem afetar sua saúde", diariamente. Para isso, os alunos utilizam o modelo da taxa de metabolismo basal, que considera a altura, a idade e a massa de uma pessoa, bem como o perfil de um dos componentes do grupo, para realização dos cálculos. Justificam a importância do estudo no que se refere a "ajudar a criar uma consciência do quão mal pode fazer um simples refrigerante de $600 \mathrm{~mL}$ ".

Nesta investigação, que poderia ser realizada mesmo sem a estrutura de um laboratório de química, os estudantes fizeram uso dos conceitos matemáticos de função, proporção e gráficos.

A investigação realizada na atividade de G3 - Comportamento do probiótico em relação à temperatura -, tinha a intenção de entender "o desempenho dos probióticos contidos no leite fermentado em relação ao tempo e à temperatura". Os alunos atentam para a importância de o consumidor seguir as recomendações do fabricante e, neste sentido, denotam a preocupação do trabalho em constatar, via experimentação, de onde são suscitadas algumas destas recomendações.

O processo de coleta de dados se deu a partir de uma amostra de leite fermentado $(80 \mathrm{~mL})$, de um termômetro digital para aferir temperaturas, um copo transparente e um forno micro-ondas para aquecimento do líquido (processo apresentado na Figura 5).

Figura 5 - Procedimentos realizados na atividade experimental desenvolvida por G3

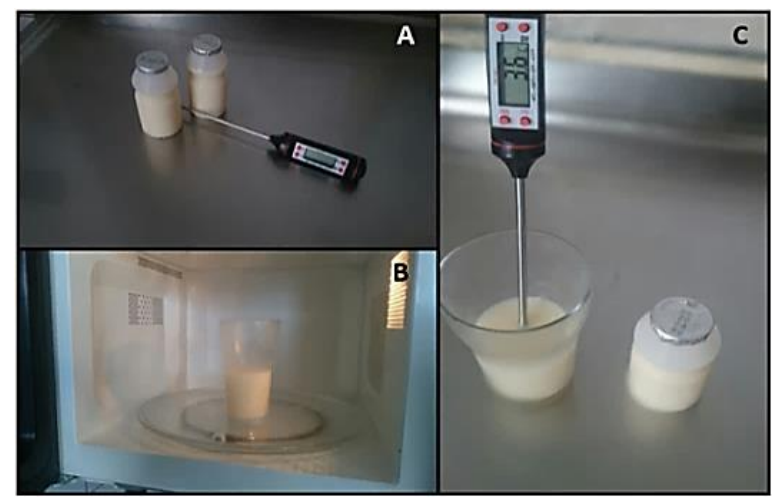

Fonte: Relatório dos alunos.

Durante o aquecimento, os alunos realizavam medidas da temperatura do líquido de 5 em 5 segundos, até atingir 70 segundos (dados apresentados no Quadro 3). Com o experimento, o grupo validou a recomendação do fabricante de que é recomendado que a ingestão do probiótico se dê quando a sua temperatura é mantida entre $0^{\circ} \mathrm{C}$ e $50^{\circ} \mathrm{C}$, "pois em uma temperatura abaixo de zero, os probióticos (pró-vida) estão em um estado congelado e parados, e acima de $50^{\circ} \mathrm{C}$ eles reduzem sua quantidade".

A constatação se deu, também, via modelo matemático a partir das informações coletadas. A interpretação gráfica permitiu aos alunos inferir que a eficácia do pró-vida no organismo humano está no intervalo de tempo $[0,65]$ segundos de aquecimento, o que corresponde a aproximadamente $50^{\circ} \mathrm{C}$ de temperatura, de modo que após esse intervalo, $\mathrm{o}$ comportamento pró-vida se torna ineficaz. A representação gráfica e a expressão algébrica correspondente seguem na Figura 6. 
Quadro 3 - Temperatura do probiótico em relação ao tempo de aquecimento

\begin{tabular}{|c|c|c|}
\hline Tempo & Temperatura & Observação \\
\hline 0 & 1,3 & O líquido apresenta coloração amarela e está superficialmente sólido. \\
\hline 5 & 3,6 & Mesma coloração, porém totalmente líquido. \\
\hline 10 & 4,0 & Mesma coloração, porém totalmente líquido. \\
\hline 15 & 6,3 & Mesma coloração, porém totalmente líquido. \\
\hline 20 & 7,4 & Mesma coloração, porém totalmente líquido. \\
\hline 25 & 14,1 & Mesma coloração, porém totalmente líquido. \\
\hline 30 & 17,3 & Mesma coloração, porém totalmente líquido. \\
\hline 35 & 21,9 & Mesma coloração, porém totalmente líquido. \\
\hline 40 & 25,2 & Mesma coloração, porém totalmente líquido. \\
\hline 45 & 28,5 & Mesma coloração, porém totalmente líquido. \\
\hline 50 & 32,3 & Mesma coloração, porém totalmente líquido. \\
\hline 55 & 37,9 & Mesma coloração, porém totalmente líquido. \\
\hline 60 & 44,7 & Mesma coloração, porém parcialmente viscoso. \\
\hline 65 & 49,8 & Mesma coloração, porém parcialmente viscoso. \\
\hline 70 & 51,5 & Mesma coloração, porém parcialmente viscoso. \\
\hline
\end{tabular}

Fonte: Relatório dos alunos.

Figura 6 - Modelo matemático da temperatura do probiótico em relação ao tempo de aquecimento

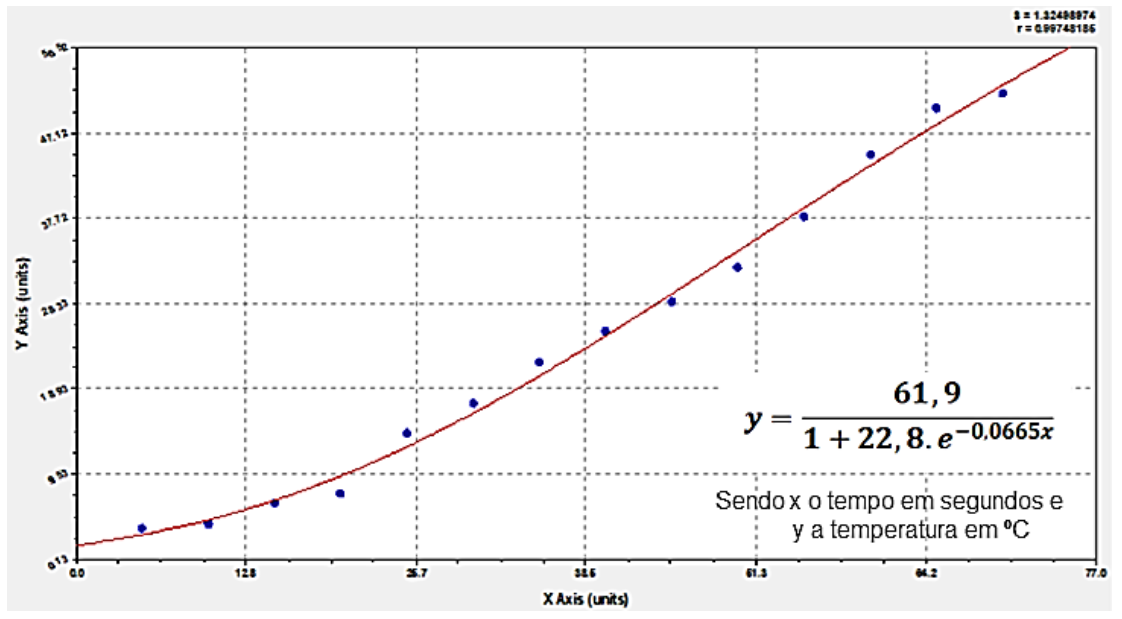

Fonte: Relatório dos alunos.

\section{Uma análise acerca das atividades experimentais investigativas no contexto de atividades de modelagem matemática}

Ao realizar uma leitura atenta dos relatórios escritos pelos alunos, buscamos indícios que permitissem realizar inferências acerca da nossa questão de pesquisa - Como se configuram atividades experimentais investigativas desenvolvidas por alunos do curso de Licenciatura em Química no contexto de atividades de Modelagem Matemática?. Neste contexto, depois de realizar aproximações entre os elementos destacados da análise a partir do conjunto das três atividades desenvolvidas, buscamos construir agrupamentos para os quais diferentes aspectos da análise convergissem. É assim que emergem os agrupamentos: 
i) Atividade experimental investigativa como um jeito de "visualizar" ${ }^{8}$ os conceitos da área de química na prática;

ii) Atividade experimental investigativa como meio de possibilitar a verificação/confirmação de dados obtidos via outras fontes (rótulo, literatura, etc.);

iii) Atividade experimental investigativa como precursora de reflexões relacionadas a aspectos socioculturais;

iv) Atividade experimental investigativa como disparadora de discussões matemáticas contextualizadas;

v) Atividade experimental investigativa como possibilidade de os alunos, desde o início do curso, vivenciarem ações características de uma atividade de pesquisa, tais como produzir e organizar dados, utilizando-os para pensar sobre um problema.

No que diz respeito ao primeiro agrupamento - atividade experimental investigativa como um jeito de "visualizar" os conceitos da área de química na prática - os alunos apontaram a importância de práticas tanto para entender e justificar as recomendações do fabricante de um produto quanto para "ver" conceitos da química na prática. O que está em consonância com as implicações da promoção de atividades investigativas com enfoque experimental, visto que os alunos precisam tomar decisões "julgando a consistência dos diversos dados obtidos, a validade de um determinado modelo teórico para explicá-los" (SILVA; TRIVELATO, 2017, p. 150).

Em relação às recomendações do fabricante, na situação da Temperatura do Probiótico, por exemplo, os alunos afirmaram que "Através deste trabalho pode-se identificar a importância de seguir as recomendações dadas pelo fabricante", ou ainda, que verificaram, via experimentação e coleta de dados, que de fato "é recomendado que sua ingestão [do probiótico] seja superior a $0^{\circ} \mathrm{C}$ e inferior a $50^{\circ} \mathrm{C}$, pois em uma temperatura abaixo de zero os probióticos (pró-vida) estão em um estado congelado e parados, e acima de $50^{\circ} \mathrm{C}$ eles reduzem sua quantidade, fazendo assim, com que sua função benéfica não seja totalmente eficaz".

Já no que tange a visualização dos conceitos de química na prática, em diferentes momentos do trabalho os alunos recorriam aos conceitos da área tanto para explanar à professora e demais leitores o porquê de procederem experimentalmente como faziam, quanto para explicar o conceito em si, importante naquela situação, denotando a importância de se respaldar cientificamente para "comunicar as suas ideias e a reflectir criticamente sobre todo o percurso investigativo" (FERNANDES; SILVA, 2004, p. 46). Na situação do Açúcar nos Refrigerantes, por exemplo, os alunos manifestam que "o resultado foi satisfatório, pois foi possível visualizar nitidamente quanto de açúcar se tem em $600 \mathrm{~mL}$ de refrigerante". Ainda, conceitos como taxa de metabolismo basal e quilocalorias, foram temas discutidos no referido trabalho, assim como titulometria, pH e dureza da água foram assuntos que figuraram no trabalho Dureza da Água, e temperatura na situação do Probiótico.

Na situação da Dureza da Água, por exemplo, os alunos discutem o conceito de "dureza da água" para justificar o trabalho. Isso denota, por exemplo, que um experimento

\footnotetext{
${ }^{8}$ Os termos visualizar e visualização são empregados, neste artigo, como ação de reconhecer.
} 
desencadeia a explicação dos conteúdos utilizados nele ou que emergem no seu desenvolvimento. É neste sentido que Sasseron (2015) afirma que o Ensino por Investigação "extravasa o âmbito de uma metodologia de ensino apropriada apenas a certos conteúdos e temas" (p. 58), assim como apontam Almeida e Silva (2012) com relação ao desenvolvimento de uma atividade de modelagem matemática em que realidade e matemática passam a se integrar.

Esse primeiro agrupamento se manifesta de modo articulado com o segundo, até porque em diversos momentos dos trabalhos foi possível evidenciar a preocupação de a atividade experimental investigativa possibilitar a verificação/confirmação de informações apresentadas ou na embalagem ou na literatura.

É o que se mostrou na situação da verificação da quantidade de açúcar nos refrigerantes e na concentração de $\mathrm{CaCO}_{3}$, em mg/L, nas amostras de água. No caso da quantidade de açúcar nos refrigerantes, os alunos manifestam, ainda no objetivo do trabalho, que pretendem "comparar com dados teóricos" os valores observados no experimento. No caso da concentração de $\mathrm{CaCO}_{3}$ nas amostras de água, por sua vez, os estudantes concluem que "Ao desenvolver a APS, conclui-se uma variação na concentração relativamente pequena para as amostras $A$ e $B$, e uma variação relativamente grande em relação as amostras $C$ e $D$, dentro das incertezas envolvidas. As amostras $A$ e $B$ encontramse dentro dos padrões de água mole (concentração inferior a $50 \mathrm{mg}$ de $\mathrm{CaCO}_{3}$ por litro de água). As amostras C e D apresentaram concentração um pouco mais elevada do que as concentrações padrão, estando dentro dos padrões de água dura (150mg a 500mg de $\left.\mathrm{CaCO}_{3}\right)^{\prime}$. Para tanto, os alunos necessitaram "planear experiências simples, visando a testagem de uma dada hipótese de trabalho" (FERNANDES; SILVA, 2004, p. 46), todavia, realizando uma abordagem investigativa em que reflexões sobre o investigado se fizeram presentes. Ou seja, desenvolveram atividades que "exercitam práticas e raciocínios de comparação, análise e avaliação bastante utilizadas na prática científica" (SASSERON, 2015, p. 58).

Algumas discussões foram empreendidas pelos alunos a partir dos resultados advindos da comparação dos dados coletados via experimentação com os dados apresentados na embalagem, por exemplo. Neste sentido é que se dá o terceiro agrupamento, que considera a atividade experimental investigativa como precursora de reflexões relacionadas a aspectos socioculturais.

Esse aspecto pode ser verificado na situação referente à Dureza da Água, quando os alunos atentam para a implicação para a saúde humana do consumo de água com grandes concentrações de cálcio e magnésio. Segundo os mesmos "Relativamente à saúde humana, apesar de serem minerais essenciais à vida humana, quando ingeridos em doses elevadas, podem levar a problemas de saúde como a osteoporose, pedras nos rins, hipertensão, resistência à insulina, entre outros".

Na situação do Probiótico, por exemplo, os alunos justificam a importância de investigar o tema, uma vez que "A busca pela qualidade de vida é uma preocupação cada vez maior no âmbito de uma sociedade e com isso as pessoas visam por suplementos alimentares que auxiliam a uma vida saudável. Sustentando nesse princípio, a ingestão de probióticos tem tido uma alta procura destinada a esse fim".

Mas é na situação do Açúcar nos Refrigerantes que, acreditamos, esse aspecto se revela de modo mais interessante. Isso porque os alunos verificam que a quantidade de açúcar aferida nos experimentos, em duas das quatro amostras, se mostra com uma 
quantidade significativamente superior à quantidade enunciada no rótulo da embalagem, como podemos constatar na Figura 4. Neste contexto é que escrevem: "Com a quantidade de açúcar obtida nas coletas dos refrigerantes de 4 marcas mostradas obtiveram-se algumas informações interessantes, tais como a marca A e a marca C, pois a quantidade de açúcar aproxima-se ao que as embalagens apresentam, ao contrário da marca B e da marca $D$, que ficam distantes do que a sua embalagem apresenta. $O$ valor apresentado pode ser grande problema, pois a quantidade " $x$ " mostrada ao cliente não é verdadeira segundo 0 experimento realizado, pois foi calculado quase o dobro de açúcar".

Além dessa constatação, apontam que a divulgação do trabalho realizado "pode ajudar a criar uma consciência do quão mal pode fazer um simples refrigerante de $600 \mathrm{~mL}$ ", bem como pode ajudar "a calcular a quantidade de açúcar que uma pessoa pode ingerir sem afetar sua saúde". Atentam, ainda, que "o consumo exagerado de refrigerantes pode fazer mal à saúde da sociedade, aumentando o risco de surgimento de cáries, por exemplo, já que o ácido fosfórico atua de forma negativa no esmalte do dente".

Embora as análises da presente pesquisa se debrucem nos trabalhos escritos produzidos pelos alunos no âmbito da disciplina de Cálculo Diferencial e Integral 1, e não sejam conhecidos os debates que desencadearam as frases utilizadas nos parágrafos supracitados, é possível inferir que a apresentação de tais informações denota a preocupação dos alunos com os aspectos socioculturais relacionados aos seus temas de trabalho que, ora justificam a escolha e desenvolvimento do tema, ora incidem sobre os resultados do experimento, por vezes causando surpresa como no caso da quantidade de açúcar nos refrigerantes ser muito superior ao enunciado em suas embalagens. Isso se configura por se estabelecer um ambiente em que se possibilite "aos alunos expressarem seus pontos de vista durante as discussões e serem reflexivos" (SILVA; MORTIMER, 2011, p. 119).

As interpretações que realizam os alunos depois do desenvolvimento da atividade, em muitos momentos, são possibilitadas pelo ferramental matemático. É donde decorre o quarto agrupamento da análise: a atividade experimental investigativa como disparadora de discussões matemáticas contextualizadas.

$\mathrm{Na}$ situação do Probiótico, por exemplo, os alunos recorreram aos softwares matemáticos, Curve Expert e GeoGebra, para realizar um ajuste de curva em relação aos pares ordenados (tempo de aquecimento no micro-ondas, temperatura do probiótico). Obtiveram o modelo matemático expresso por $y=\frac{61,9}{1+22,8 e^{-0,0665 x}}$ em que $x$ representa 0 tempo de aquecimento do probiótico no micro-ondas, em segundos, e y representa a temperatura do probiótico, em graus Celsius. Com isso, possibilita-se aos alunos a oportunidade "em reconhecer, planejar ou selecionar testes experimentais consistentes, ou seja, situações nas quais apenas a variável cujo efeito deseja-se determinar sofre alterações, enquanto as demais variáveis são mantidas constantes" (GOMES; BORGES; JUSTI, 2008, p. 193), o que permite uma interpretação refinada da matemática e da situação em estudo.

No caso, tanto a função dada em sua representação algébrica, quanto o gráfico e tabela associados, possibilitaram aos alunos concluir que a eficácia do probiótico no organismo humano está no intervalo $[0,65]$ segundos, e após esse intervalo passa a ser ineficaz. Nesta abordagem podemos evidenciar que conhecimentos matemáticos e conhecimentos químicos estiveram atrelados à atividade experimental investigativa no sentido discutido por Geiger, Ärlebäck e Frejd (2016, p. 208) em que os alunos "reconstroem o conhecimento que já adquiriram ao se envolver com o processo de modelagem". 
Outra situação em que os alunos discutem a Matemática presente na investigação, associando-a ao contexto de sua utilização, é a da quantidade de açúcar em refrigerantes. Se por um lado, o gráfico de colunas é que suscita interpretações em relação à disparidade entre a quantidade de açúcar declarada na embalagem e a verificada experimentalmente, por outro, é a intenção de verificar quanto de açúcar uma pessoa pode consumir diariamente e quanto de refrigerante poderia ser ingerido se esse consumo de açúcar fosse advindo apenas de refrigerantes, que gera uma investigação em termos de qual seria o perfil dessa pessoa, e como os dados se comportariam se mantivéssemos fixos a altura e a idade da pessoa, mas se variássemos a massa. Isso forneceria quanto de kcal uma pessoa poderia ingerir (Quadro 4).

Quadro 4 - Cálculo dos kcal que podem ser consumidos diariamente para um perfil específico

\begin{tabular}{|c|c|c|c|}
\hline Massa $(\mathrm{em} \mathrm{kg})$ & Altura $(\mathrm{em} \mathrm{cm})$ & Idade (em anos) & Taxa metabólica basal (em kcal) \\
\hline 75 & 180 & 25 & 2171 \\
\hline 80 & 180 & 25 & 2240 \\
\hline 85 & 180 & 25 & 2309 \\
\hline 90 & 180 & 25 & 2378 \\
\hline 95 & 180 & 25 & 2447 \\
\hline 100 & 180 & 25 & 2516 \\
\hline
\end{tabular}

Fonte: Relatório dos alunos.

O modelo matemático utilizado nessa ocasião, por sua vez, foi obtido na literatura especializada e refere-se ao cálculo da Taxa Metabólica Basal; $C=13,8 p+5 h-6,8 i+66$, em que $p$ representa a massa da pessoa, em quilogramas, $h$ representa a altura, em centímetros, e $i$, a idade, em anos.

O que fica evidente é que os alunos buscam na literatura validar a abordagem matemática utilizada, aplicando-a ao contexto da química, não se limitando a fazer a abordagem da quantidade de açúcar nos refrigerantes. Neste aspecto, de certa forma, a atividade de modelagem desencadeou uma ação em que os alunos buscaram "a resolução do problema por meio de procedimentos adequados e a análise da solução que implica numa validação, identificando a sua aceitabilidade ou não" (ALMEIDA; FERRUZZI, 2009, p. 121).

O fato de os alunos terem recorrido à literatura para pesquisar como calcular a taxa metabólica basal, assim como para planejar a realização de um experimento e validar alguns dos resultados encontrados, denotam características específicas da atividade científica. Dessa observação decorre o quinto e último agrupamento desta pesquisa, o que considera a atividade experimental investigativa como possibilidade de os alunos, desde o início do curso, vivenciarem ações características de uma atividade de pesquisa, tais como produzir e organizar dados, utilizando-os para pensar sobre um problema. Isso está em consonância com a alfabetização científica defendida por Rosa, Suart e Marcondes (2017, p. 55), no contexto do ensino, em que:

\footnotetext{
A fim de proporcionar uma melhor formação cidadã, é necessário oferecer aos indivíduos, habilidades relacionadas ao processo de alfabetização científica, de forma a proporcionar uma melhor compreensão e uma atuação mais crítica e reflexiva no desenvolvimento da sociedade como um todo.
} 
No que se refere à produção e organização de dados, todas as atividades de modelagem matemática desenvolvidas apresentaram com detalhamento a metodologia empregada no experimento, em que os alunos souberam "coligir os dados por certo crivo lógico, que resulte em uma formulação que expresse certa regularidade entre os acontecimentos da situação ao fenômeno estudado" (BIEMBENGUT, 2016, p. 119). Além disso, registraram com fotos os procedimentos utilizados, justificando e discutindo, quando julgavam necessário, os conceitos que emergiam na investigação, estabelecendo "uma complexa relação estrutural entre duas entidades de diferente natureza epistemológica: a situação a ser modelada e o sistema matemático" (ALMEIDA; SILVA, 2015, p. 45). Isso "possibilitou aos alunos "pensar cientificamente", permitindo-lhes resolver um problema prático do seu próprio interesse" (FERNANDES; SILVA, 2004, p. 57).

A apresentação dos dados que foram obtidos na atividade experimental, em uma linguagem específica da química, área de formação dos alunos, denota que, por meio da experimentação, deixam de apenas interpretar os quadros, as tabelas e os gráficos apresentados pelos docentes em situações, muitas vezes, fictícias, para produzir esses dados e organizá-los de modo a permitir a outros a realização de leituras, segundo cultura específica da área da Química.

Na Figura 7, esquematizamos os agrupamentos para os quais diferentes aspectos da análise das atividades experimentais convergiram.

Figura 7 - Esquema que representa os agrupamentos que emergiram da análise das atividades experimentais

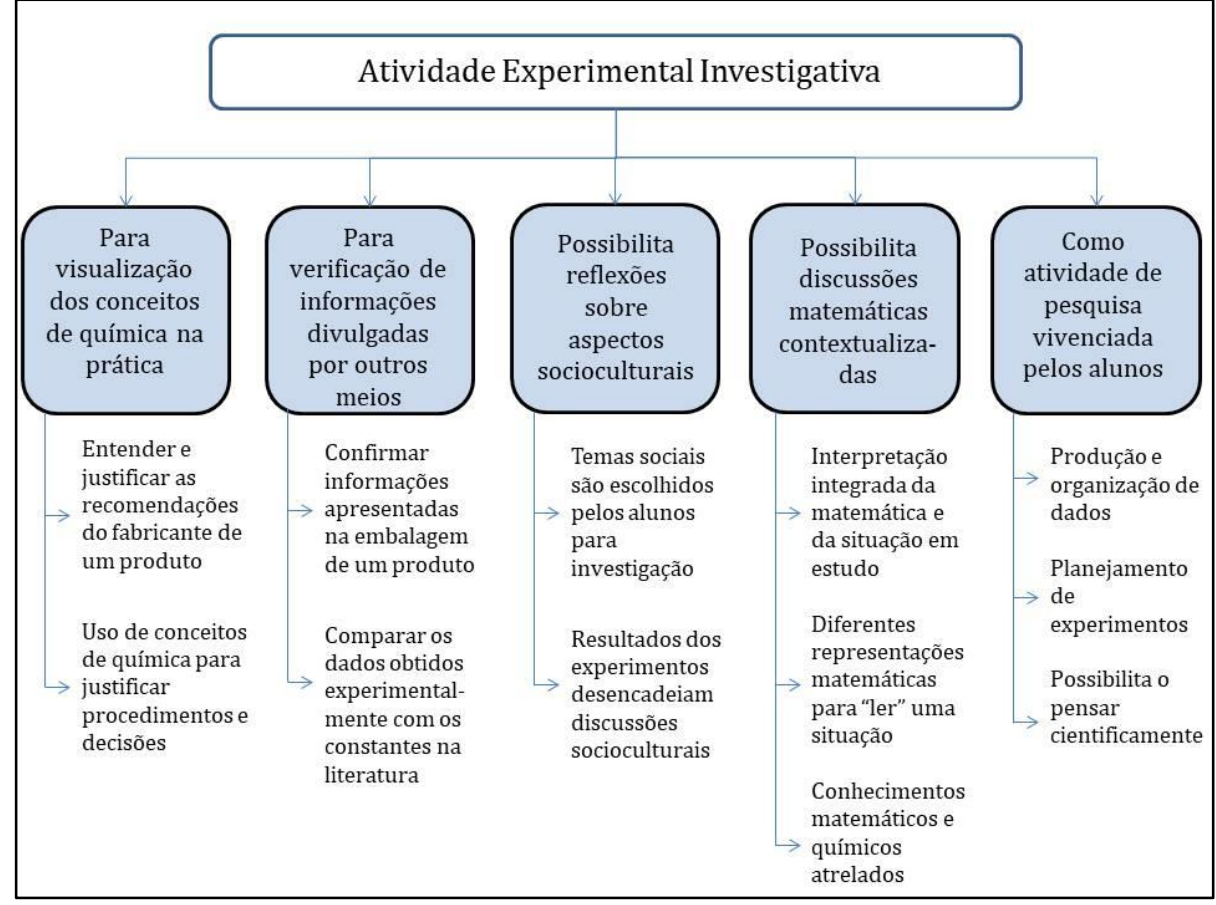

Fonte: Autores.

\section{Considerações finais}

Tendo como engajamento propor nas aulas de Cálculo Diferencial e Integral atividades investigativas que possibilitem a relação entre conteúdos matemáticos e aqueles próprios 
dos cursos nos quais a Matemática está presente, evidenciamos que atividades experimentais ocuparam destaque no curso de Licenciatura em Química, desde o início dos nossos trabalhos em 2014.

Entendemos que no referido curso, atividades experimentais são corriqueiras, sendo que o manejo dos materiais não é um obstáculo para os estudantes. Todavia, não somente o manejo de materiais se faz necessário quando os alunos se envolvem com atividades experimentais investigativas no contexto de atividades de modelagem matemática. Para além de se apresentar uma organizada estrutura para a realização dos procedimentos, há de se buscar reflexões para uma situação-problema por meio de levantamento de hipóteses, realização de análises de dados oriundos de sua realidade, obtendo novas informações que devem ser interpretadas, validadas e comunicadas.

No entanto, um trabalho que exige investigação e tomada de decisões pode apresentar diferentes configurações visto que realidades distintas se fazem presentes em uma sala de aula. Quando a atividade investigativa é solicitada no âmbito de uma aula de matemática se caracterizando como uma atividade de modelagem, o problema é a gênese do processo investigativo e a solução para tal é o objetivo final. Para isso, há necessidade de realizar procedimentos matemáticos com vistas a obter um modelo matemático. Como "não existem regras fixas ou um único caminho a ser seguido" (SOUZA; JUSTI, 2010, p. 4) para deduzir um modelo, mas uma finalidade que é realizar uma interpretação matemática, essas configurações podem ser elucidadas.

Com isso, ao fazermos uma análise de três atividades experimentais investigativas desenvolvidas por três grupos de alunos de turmas distintas, nos anos de 2015, 2016 e 2017, do curso de Licenciatura em Química no contexto de atividades de modelagem matemática, emergiram cinco agrupamentos elaborados pela análise do conjunto das três atividades que configuram atividades experimentais investigativas como: um jeito de "visualizar" os conceitos da área de química na prática; como meio de possibilitar a verificação/confirmação de dados obtidos via outras fontes (rótulo, literatura, etc.); como precursora de reflexões relacionadas a aspectos socioculturais; como disparadora de discussões matemáticas contextualizadas; como possibilidade de os alunos, desde o início do curso, vivenciarem ações características de uma atividade de pesquisa, tais como produzir e organizar dados, utilizando-os para pensar sobre um problema.

Neste sentido, acreditamos que nossa proposta de Atividade Prática Supervisionada tem atendido alguns requisitos para a formação do professor em Química, com relação ao contato com diferentes metodologias como apontam Rosa, Suart e Marcondes (2017).

Além de ser uma abordagem didática para o ensino, as "atividades experimentais investigativas também têm o potencial de aumentar as relações sociais, atitudes e o crescimento cognitivo" (SUART; MARCONDES, 2009, p. 70) entre os estudantes que as desenvolvem. Isto se deve ao fato de serem atividades cooperativas. Essa abordagem não foi destacada na pesquisa, devido às limitações que relatórios escritos apresentam. Para tanto, se faz necessário um acompanhamento presencial do pesquisador, sendo uma possibilidade de pesquisa futura.

Finalizamos esse artigo apontando que as configurações elucidadas não estão sedimentadas, podendo ser aprimoradas, complementadas ou mesmo reformuladas, visto que foram construídas para um grupo específico de alunos. 


\section{Referências}

ALMEIDA, L. M. W.; FERRUZZI, E. C. Uma aproximação socioepistemológica para a modelagem matemática. Alexandria. Revista de Educação em Ciência e Tecnologia, 2(2). 117-134, 2009.

ALMEIDA, L. M. W.; SILVA, K. A. P. A Ação dos Signos e o Conhecimento dos Alunos em Atividades de Modelagem Matemática. Bolema, 31(57). 202-2019, 2017.

ALMEIDA, L. M. W.; SILVA, K. A. P. Semiótica e as ações cognitivas dos alunos em atividades de modelagem matemática: um olhar sobre os modos de inferência. Ciência \& Educação, 18(3). 623-642, 2012.

ALMEIDA, L. M. W.; SILVA, K. A. P. The Meaning of the Problem in a Mathematical Modelling Activity. In STILLMAN, G. A.; BLUM, W.; BIEMBENGUT, M. S. (Eds.), Mathematical Modelling in Education Research and Practice: cultural, social and cognitive influences (45-54). New York: Springer, 2015

ALMEIDA, L. W.; SILVA, K. P.; VERTUAN, R. E. Modelagem Matemática na Educação Básica. São Paulo: Contexto, 2012.

ARAÚJO, J. L.; CAMPOS, I. S. Negotiating the Use of Mathematics in a Mathematical Modelling Project. In STILLMAN, G. A.; BLUM, W.; BIEMBENGUT, M. S. (Eds.), Mathematical Modelling in Education Research and Practice: cultural, social and cognitive influences (283291). New York: Springer, 2015.

BIEMBENGUT, M. S. Modelagem na Educação Matemática e na Ciência. São Paulo: Editora Livraria da Física, 2016.

CARVALHO, A. M. P. O ensino de Ciências e a proposição de sequências de ensino investigativas. In CARVALHO, A. M. P. (Org.). Ensino de Ciências por investigação: condições para implementação em sala de aula (1-20). São Paulo: Cengage Learning, 2013.

FERNANDES, M. M.; SILVA, M. H. S.. O trabalho experimental de investigação: das expectativas dos alunos às potencialidades no desenvolvimento de competências. Revista Brasileira de Pesquisa em Educação em Ciências, 4(1). 45-58, 2004.

FERRUZZI, E. C.; ALMEIDA, L. M. W. Diálogos em modelagem matemática. Ciência \& Educação, 21(2). 377-394, 2015.

GEIGER, V.; ÄRLEBÄCK, J. B.; FREJD, P. Interpreting Curricula to find: opportunities for modeling: case studies from Australia and Sweden. In NCTM. Mathematical Modeling and Modeling Mathematics (207-215). USA: APM, 2016.

GOMES, A. D. T.; BORGES, A. T.; JUSTI, R. Processos e conhecimentos envolvidos na realização de atividades práticas: revisão da literatura e implicações para a pesquisa. Investigações em Ensino de Ciências, 13(2). 187-207, 2008.

IGLIORI, S. B. C.; BELtRÃO, M. E. P. Ensino de Cálculo pela Modelagem Matemática e Aplicações em um Curso Superior Tecnológico. Unión: Revista Iberoamericanade Educación Matemática, 42. 55-76, 2015. 
LESH, R.. Research design in mathematics education: Focusing on design experiments. In ENGLISH, L. D. (Ed.). Handbook of International Research in Mathematics Education (27-49). New Jersey: Lawrence Erlbaum Associates, 2002.

ROSA, L. M. R.; SUART, R. C.; MARCONDES, M. E. R. Regência e análise de uma sequência de aulas de química: contribuições para a formação inicial docente reflexiva. Ciência \& Educação, 23(1). 51-70, 2017.

SILVA, A. C. T.; MORTIMER, E. F. As estratégias enunciativas de uma professora de química e o engajamento disciplinar produtivo dos alunos em atividades investigativas. Revista Brasileira de Pesquisa em Educação em Ciências, 11(2). 117-138, 2011.

SASSERON, L. H. Alfabetização científica, ensino por investigação e argumentação: relações entre ciências da natureza e escola. Revista Ensaio, 17(especial). 49-67, 2015.

SILVA, K. A. P. Modelagem matemática em sala de aula: caracterização de um ambiente educacional. Revista Paranaense de Educação Matemática, 6(10). 135-157, 2017.

SILVA, M. B.; TRIVELATO, S. L. F. A mobilização do conhecimento teórico e empírico na produção de explicações e argumentos numa atividade investigativa de Biologia. Investigações em Ensino de Ciências, 22(2). 139-153, 2017.

SOUZA, V. C. A.; JUSTI, R. Estudo da utilização de modelagem como estratégia para fundamentar uma proposta de ensino relacionada à energia envolvida nas transformações químicas. Revista Brasileira de Pesquisa em Educação em Ciências, 10(2). 1-26, 2010.

SUART, R. C.; MARCONDES, M. E. R. A manifestação de habilidades cognitivas em atividades experimentais investigativas no ensino médio de química. Ciências \& Cognição, 14(1). 50-74, 2009.

ZÔMPERO, A. F.; LABURÚ, C. E. Atividades investigativas no ensino de ciências: aspectos históricos e diferentes abordagens. Ensaio Pesquisa em Educação em Ciências, 13(3). 67-80, 2011. 